This is the conference version of the paper.

The original version of this paper can be found at http://dx.doi.org/10.1080/20426445.2016.1261235

Please cite this paper as:

Li, W.; Van den Bulcke, J.; Windt, I. D.; Dhaene, J.; Mannes, D.; Lehmann, E. \& Van Acker, J. (2016). Investigating plywood behaviour in outdoor conditions International Wood Products Journal, 7, 220-224. 


\title{
Investigating plywood behaviour in outdoor conditions
}

\author{
Wanzhao Li $i^{1,2,3}$, Jan Van den Bulcke ${ }^{1,3}$, Imke De Windt ${ }^{1,3}$, Jelle Dhaene ${ }^{3}$, David \\ Mannes ${ }^{4}$, Eberhard Lehmann ${ }^{4}$, Joris Van Acker ${ }^{1,3}$ \\ 1. UGCT-Woodlab-UGent, Laboratory of Wood Technology, Faculty of Bioscience Engineering, Ghent \\ University, Coupure Links 653, 9000 Gent, Belgium \\ 2. College of Materials Science and Engineering, Nanjing Forestry University, Longpan Road 159, \\ 210037 Nanjing, China \\ 3. UGCT, Department of Physics and Astronomy, University Ghent Centre for X-ray Tomography, \\ Proeftuinstraat 86, 9000 Ghent, Belgium \\ 4. Paul Scherrer Institute (PSI), Villigen 5234, Switzerland
}

\begin{abstract}
Moisture behaviour of plywood is investigated in combination with detailed structural analysis. In the lab, neutron radiography and X-ray computed tomography (X-ray CT) were used to map the moisture distribution and internal structure of plywood respectively. In an outdoor natural weathering test, the average moisture content (MC) and moisture distribution of plywood were monitored using a continuous moisture measurement (CMM) set-up and an adapted electrical method respectively. The structural changes of the specimens during weathering were recorded by using X-ray CT. Based on the interrelationship of moisture behaviour and structure, suggestions on improving the water resistance of plywood by optimizing structure are given.
\end{abstract}

\section{KEYWORDS}

Moisture behaviour; Internal structure; Outdoor exposure; Plywood.

\section{INTRODUCTION}

Plywood is an important construction material that is used in use class 3 situations, where it is subjected to natural weathering out of ground contact (Van Acker and De Smet, 2007). As a wood-based material, plywood is prone to water uptake, which could influence its physical and mechanical properties (Drow, 1957). To increase the water resistance of plywood, extra protection methods, for instance edge sealing, coating and preservation are commonly used. Compared to the above methods, optimizing the structure of plywood is a more economic and environmental friendly way to improve water resistance and in that respect it is important to understand the influence of structure on the moisture behaviour of plywood. Neutron imaging is suitable to monitor and quantify moisture distribution due to the high attenuation of the neutron beam by hydrogen nuclei (Pleinert and Lehmann, 1997). To obtain the moisture behaviour of plywood in service, a continuous moisture measurement (CMM) and an adapted electrical method have been introduced (Van den Bulcke, et al., 2009, Li, et al., 2013). For the study of the internal structure of wood based materials, X-ray CT scanning has been regarded as an effective method (Chen, et al., 2009). The objective of this research is to monitor the moisture behaviour of plywood in the laboratory and in outdoor exposure conditions. The monitored moisture behaviour was further analysed by combining the internal structure of specimens obtained with X-ray CT scanning. Finally, based on the interrelationship of moisture behaviour and internal structure, some suggestions on improving the water resistance of plywood by optimizing its structure, e.g. veneer wood species, glue type, veneer structure, were given.

\section{MATERIALS AND METHODS}

The specimens were prepared from the plywood panels listed in Table 1. 
Table 1: Plywood structure and position of electrodes starting from the exposed face of the specimen.

\begin{tabular}{|c|c|c|c|c|c|c|}
\hline Code & $\begin{array}{c}\text { Wood } \\
\text { species }\end{array}$ & $*$ Glue & $\begin{array}{c}\text { \# of } \\
\text { plies }\end{array}$ & $\begin{array}{c}* * \text { Veneers } \\
\text { Thickness }(\mathrm{mm})\end{array}$ & $\begin{array}{c}\text { Total } \\
\text { Thickness }(\mathrm{mm})\end{array}$ & $\begin{array}{c}\text { Electrodes } \\
(\text { layer })\end{array}$ \\
\hline P1 & poplar & UMF & 7 & $1.3 / 2.6 / 2.6$ & 14.9 & $2^{\text {nd }}, 3^{\text {rd }}, 4^{\text {th }}$ \\
\hline P2 & poplar & PF & 7 & $1.0 / 2.5 / 2.8$ & 14.6 & $2^{\text {nd }}, 3^{\text {rd }}, 4^{\text {th }}$ \\
\hline B1 & birch & PF & 11 & $1.4 / 1.4 / 1.4$ & 15.0 & $2^{\text {nd }}, 4^{\text {th }}, 6^{\text {th }}$ \\
\hline B2 & birch & PF & 11 & $1.9 / 1.4 / 1.45$ & 15.7 & $2^{\text {nd }}, 4^{\text {th }}, 6^{\text {th }}$ \\
\hline O1 & okoumé & PF & 7 & $1.3 / 3.0 / 2.0$ & 15.2 & $2^{\text {nd }}, 3^{\text {rd }}, 4^{\text {th }}$ \\
\hline
\end{tabular}

*PF: phenol formaldehyde glue; UMF: urea melamine formaldehyde glue.

**Veneer thickness: top veneer/inner cross/inner parallel.

\section{Experiment 1}

One specimen from each plywood panel (Table 1) was cut to the size of $10 \times 30 \times$ panel thickness $\mathrm{mm}^{3}$. All sides, except the two sides with dimension of $10 \times$ panel thickness $\mathrm{mm}^{2}$, were sealed to ensure that water uptake was only allowed from the side edge of the specimens. Before water uptake, all specimens were scanned with HECTOR, the latest system developed by the Ghent University Centre for X-ray Tomography (www.ugct.ugent.be) in collaboration with X-Ray Engineering (XRE bvba, Ghent, Belgium) (Masschaele, et al., 2013). The voxel pitch of the reconstructed volume is approximately $30 \mu \mathrm{m}$. Afterwards, one unsealed side was immersed in demineralized water. During water uptake, the specimens were scanned every 40 $\mathrm{s}$ at the neutron beam line of the Paul Scherrer Institute (PSI) in Villigen, Switzerland. The obtained neutron radiography has an approximate resolution of $68 \mu \mathrm{m} /$ pixel. To further explain some of the observed phenomena from neutron radiography, the Nanowood CT scanner (Manuel, et al., 2014), also built at the Ghent University Centre for X-ray Tomography, was used to scan regions of interest of specimens during a second water uptake experiment, after the neutron experiments. The specimens were in contact with demineralised water in the same direction as in the neutron experiments. They were removed from the water after $0,10,20,60$ and 120 minutes and at each of these intervals scanned with a resolution of approximately $20 \mu \mathrm{m}$.

\section{Experiment 2}

One specimen with the size of $100 \times 30 \times$ panel thickness $\mathrm{mm}^{3}$ from each panel listed in Table 1 was prepared. All side edges of the specimens were sealed. Electrodes were carefully installed in the different layers of the specimens to monitor the MC of these layers (Table 1) according to the method described in Li et al. (2013). Afterwards, all specimens were conditioned at $65 \%$ relative humidity $(\mathrm{RH})$ and $20{ }^{\circ} \mathrm{C}$ until constant mass prior to outdoor exposure on the CMM set-up as described in Van den Bulcke et al. (2009). The specimens were installed at an angle of $45^{\circ}$ facing south (Figure 1). Adjacent to the CMM set-up, a weather station recorded precipitation $(\mathrm{mm})$, relative humidity $(\%)$, solar radiation $\left(\mathrm{W} / \mathrm{m}^{2}\right)$ and temperature $\left({ }^{\circ} \mathrm{C}\right)$. The measurements started on the $29^{\text {th }}$ of October 2013 with recordings of weather data and CMM weighing every $5 \mathrm{~min}$, whereas electrical MC was measured every $10 \mathrm{~min}$. The measurements lasted for approximately one year. After measurement, the specimens were scanned with HECTOR. The approximated voxel pitch of these reconstructions was $20 \mu \mathrm{m}$. 


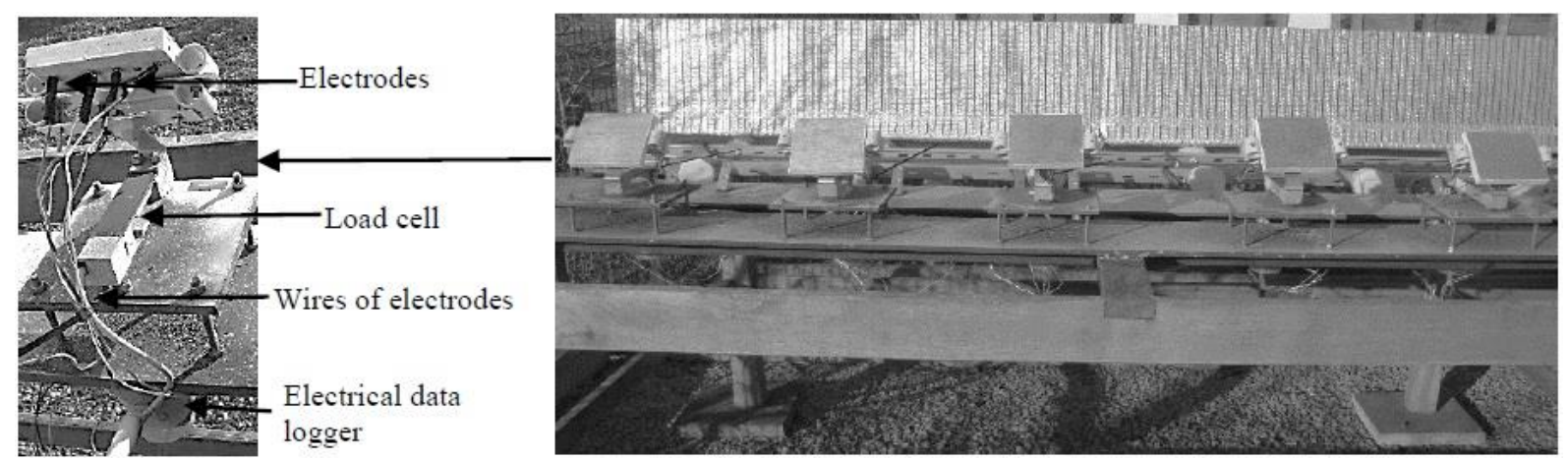

Figure 1: Outdoor set-up of specimens on the CMM (Li, et al., accepted)

\section{Experiment 1}

\section{RESULTS AND DISCUSSION}

Most of the water in P1 was trapped in the layers with upward longitudinal direction, this panel was glued with UMF (Figure 2). For P2, B1 and B2, water penetrated the glue line and moved to the adjacent layers. Compared to $\mathrm{PF}$, the UMF resin provided a strong water barrier. In general, water can easily move in the longitudinal direction, however, the speed of water movement was different. To understand this phenomenon, the structure of layers with slow water movement speed was investigated and shown in Figure 3.

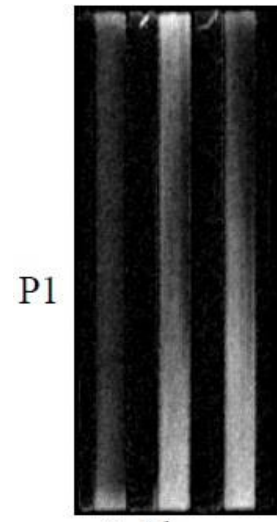

2.4 hours

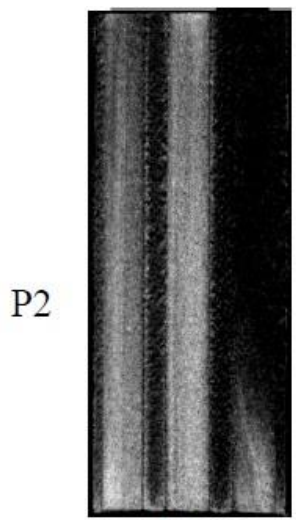

3.4 hours
B1

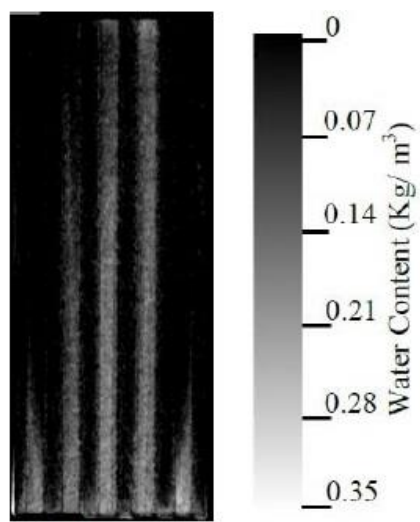

3.4 hours

Figure 2: Water (white colour) distribution after uptake from the side edge obtained with neutron radiography (Li, et al., 2014)

In layers with less water, the grain direction was not parallel to the glue line (Figure 3) and, therefore, water had to move along a mixed longitudial and radial direction. Hence, the water movement speed in these layers was slow. Similarly with water uptake from the side edge, the grain direction of the veneer can also influence water movement at the surface of plywood. If the grain direction of veneer parallels the glue line, water would move along the radial direction when water uptake occurs at the surface of plywood. Hence, when the grain direction of veneer is not parallel with the glue line it causes transport to occur in a hybrid longitudial and radial direction, which can increase water movement at the surface of plywood. 

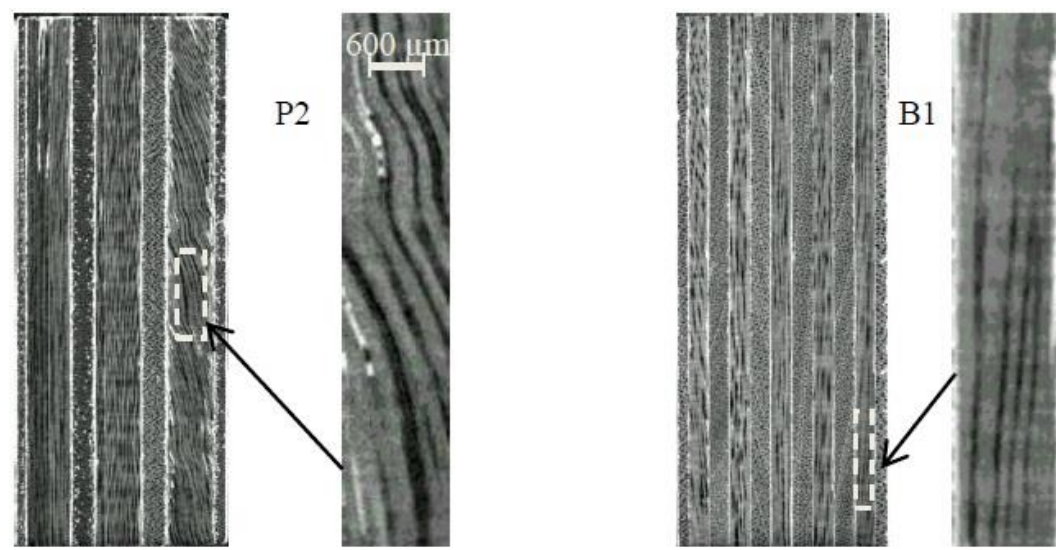

Figure 3: X-ray CT cross-sections of plywood and detailed microstructure of veneers (Li, et al., 2014)

Compared to the original image (Figure 4, top), the additional white colour in the images of samples after water absorption (Figure 4, bottom) represents the absorbed water. In the poplar plywood water mainly appears in veneer checks. Veneer checks are thus one of the main reasons for water uptake in plywood. Small gaps near the glue line could also induce water uptake.

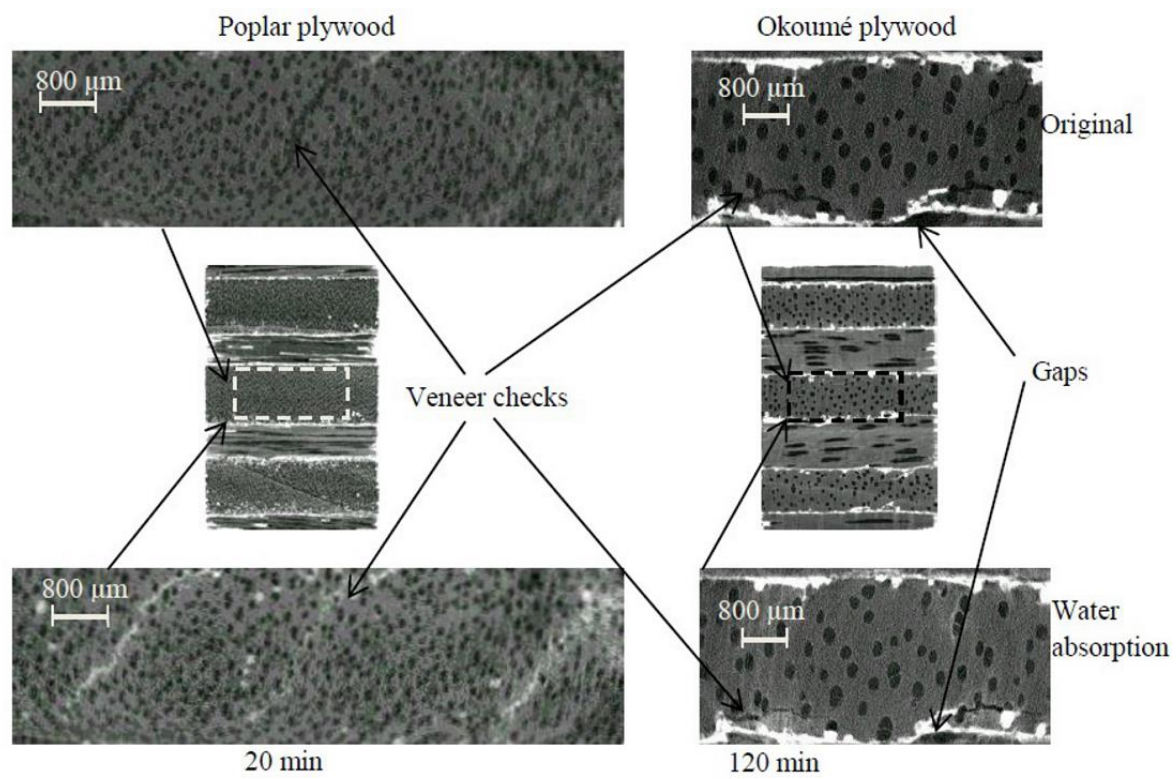

Figure 4: Microstructure of poplar plywood and okoumé plywood obtained by X-ray CT scanning before (top) and after (bottom) water uptake (Li, et al., 2014)

\section{Experiment 2}

The water distribution in different layers of plywood in outdoor exposure was not homogenous (Figure 5). Therefore average MC values cannot properly represent the interior moisture behaviour of specimens. Figure 5 shows that rainfall is the main reason for MC increase, while the intense solar radiation and high temperature can induce MC decrease. Compared to the internal MC, average MC is easily affected by the weathering conditions. Specifically, average MC increases at every rainfall event and almost simultaneously decreases when precipitation stops. Inside the panel the MC increase and decrease obviously lags the periods of precipitation and of intense solar radiation respectively. 

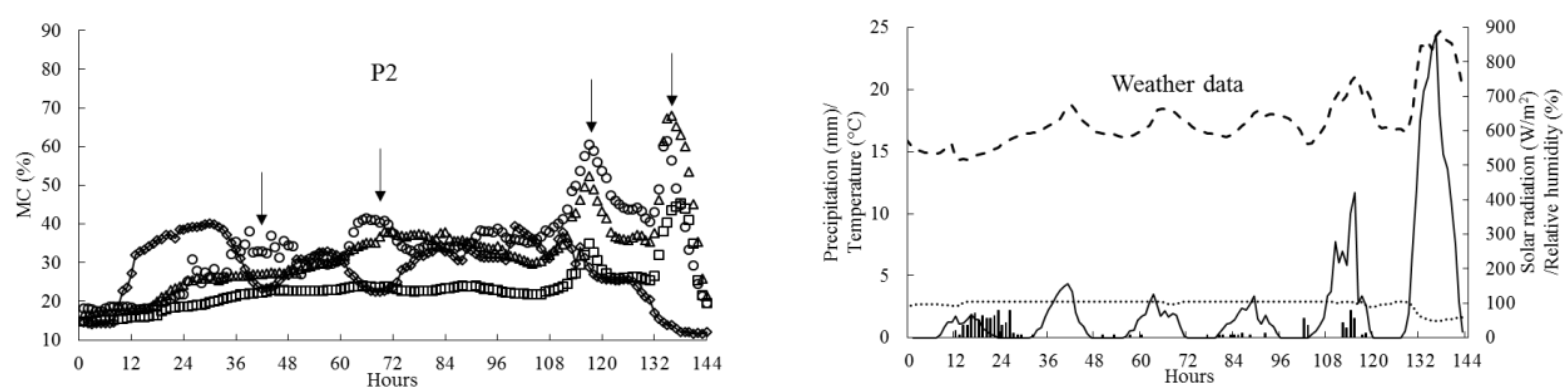

Figure 5: Hourly MC and weather data from the $9^{\text {th }}$ to $14^{\text {th }}$ of July 2014. $\circ=M C$ of the $2^{\text {nd }}$ layer, $\Delta=M C$ of the $3^{\text {rd }}$ layer, $\square=M C$ of the $4^{\text {th }}$ layer, $\diamond=$ the average $M C$, bar graph= precipitation, solid line $=$ solar radiation, dashed line $=$ temperature, dotted line $=$ relative humidity (Li, et al., accepted)

In this research, 20\% MC was used as the reference value for calculation of time of wetness (TOW) in different layers of plywood specimens exposed outdoors (Figure 6). The water resistance of $\mathrm{P} 1$ and $\mathrm{O} 1$ was better than the other three types of plywood panels because P1 was glued with UMF and $\mathrm{O} 1$ was made from okoumé which has good water resistance. Moisture accumulation for most of the specimens caused a high TOW in the second layer. For P1, most of the water accumulated in the third layer, which could be, partially due to water penetrating via the voids of the holes drilled to install the electrodes.

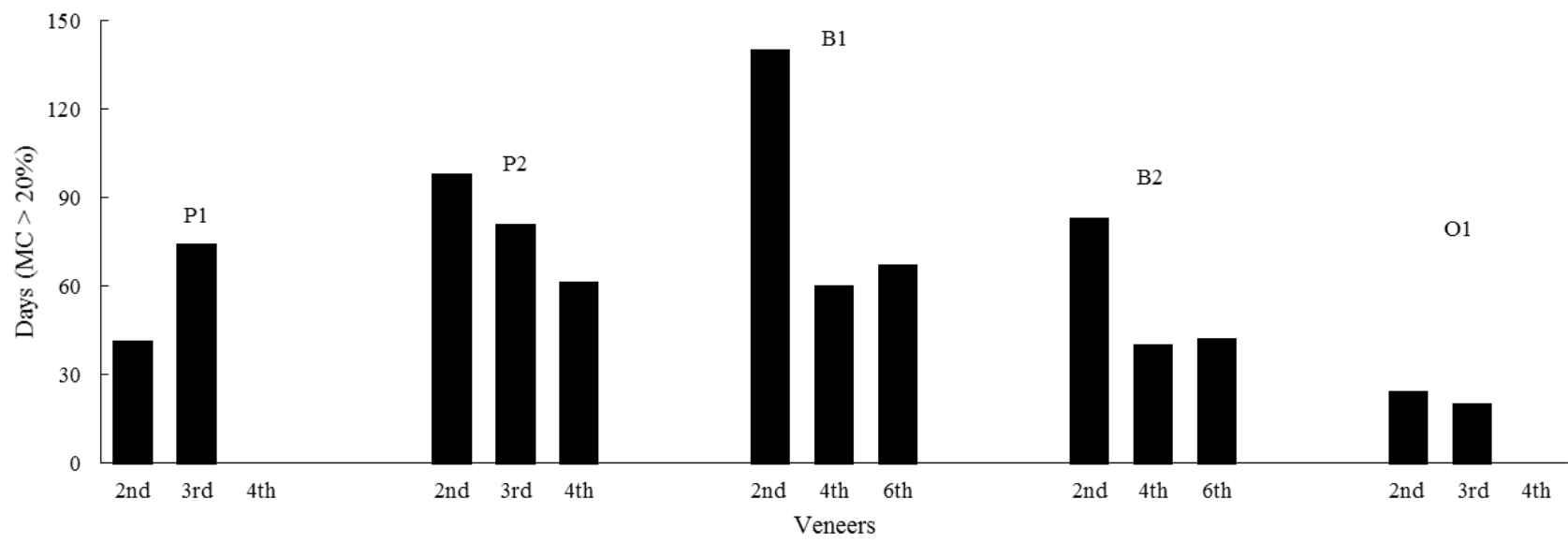

Figure 6: Amount of days with an MC higher than 20\% (TOW) in different layers of the specimens (Li, et al., accepted)

The structure of B1 was similar to B2, but B1 had a thinner top veneer. In order to investigate the clear TOW difference of these two specimens, the distribution of days with MC higher than $20 \%$ was calculated and is shown in Figure 7. At the beginning of the exposure, there was a lag in moisture accumulation in the monitored layers of B2, which could be due to the thick top veneer acting as a water reservoir. In B2 more water, and especially a long wetting time, was needed for water to cross the top veneer and to reach the inner layers. The higher TOW of B1 in the last exposure period could be the result of the structural changes during outdoor exposure. Figure 8 shows the top veneer structure of B1 and B2 after approximately one year exposure. Compared to B2, the cracks in the top veneer of B1 were wider, larger and closer to the glue line. Hence, water more easily reached the glue line and penetrated to the next layer, causing a high TOW in the inner layers. 


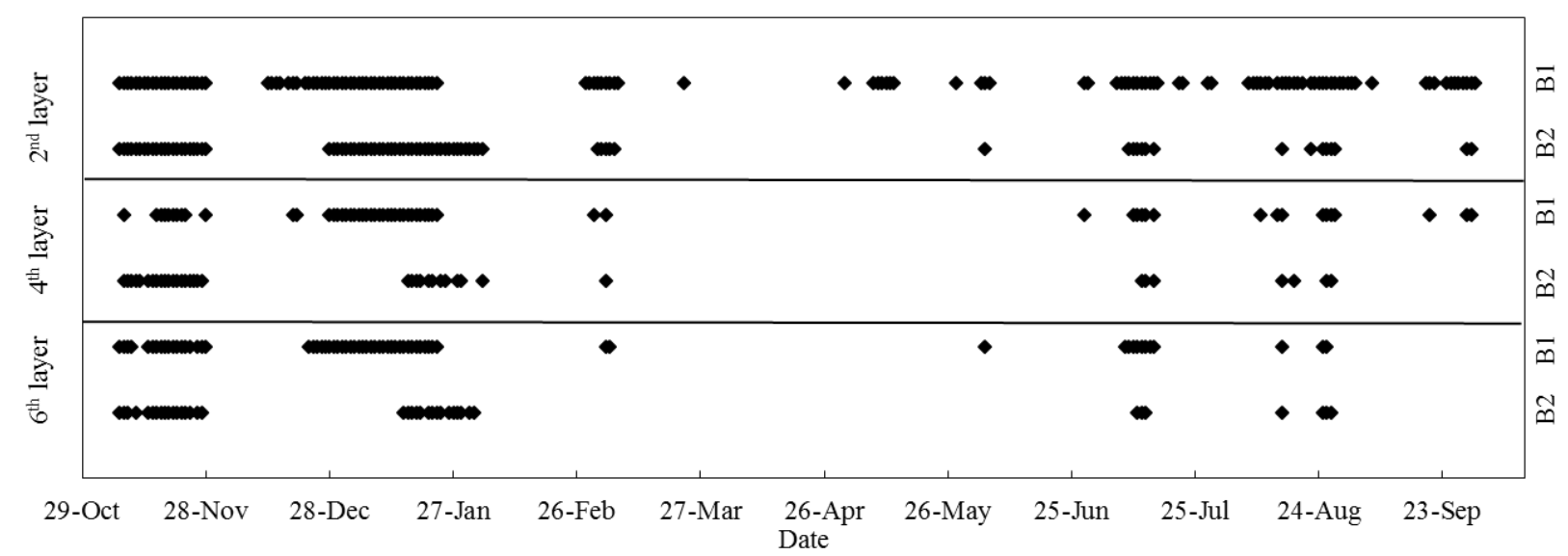

Figure 7: Days with MC higher than 20\% (TOW) in the different layers of B1 and B2 (Li, et al., accepted)

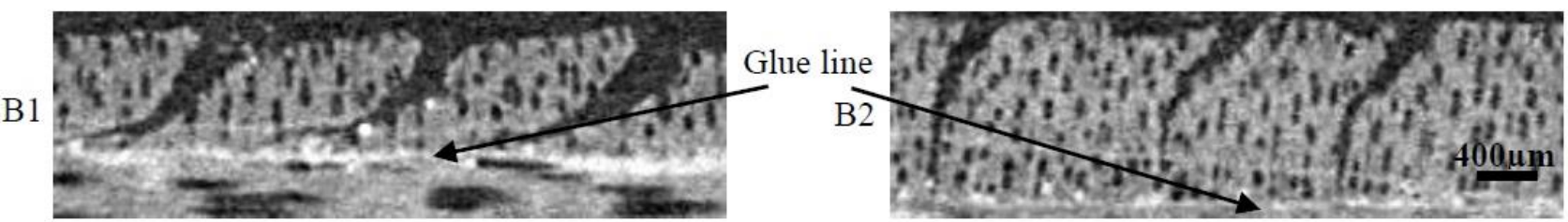

Figure 8: Structure of the top veneers (top layer in the images) of B1 and B2 after approximately one year exposure obtained with X-ray CT scanning ( $\mathrm{Li}$, et al., accepted)

\section{CONCLUSIONS}

Several factors have been shown to influence the water resistance of plywood. Specifically, $\mathrm{UMF}$ has a better water resistance than PF. Veneers with non-parallel grain direction to the glue line can decrease the face water resistance and increase water resistance of the side edges of plywood. Veneer checks and gaps between veneers can increase water uptake of plywood. During outdoor exposure, the moisture distribution in different layers of plywood is not homogenous and the second layer can accumulate moisture. Compared to the average $\mathrm{MC}$, monitoring the $\mathrm{MC}$ in different layers separately can reveal the interior moisture behaviour of plywood properly. Veneer, wood species and the type of glue play a key role on water resistance of plywood panels. Cracks emerging during outdoor exposure are the main factor in the decrease of water resistance in plywood.

According to the above findings, the following suggestions on improving water resistance of plywood can be given:

1. Wood species with good water resistance and durability are selected for top veneers. During veneer preparation, it is necessary to reduce veneer checks and control the grain direction so that is runs parallel to the face direction.

2. Veneers made from wood species with low water resistance and good strength properties are best suited for the inner layers of plywood. Veneers with non-parallel grain direction to the glue line are suited as inner layers of plywood, which can increase the water resistance at the side edges.

3. We suggest the use of an adhesive with good water barrier properties to glue the outer layers. 


\section{ACKNOWLEDGEMENT}

The authors would like to thank Mr. Rik De Rycke, Mr. Stijn Willen and Mr. Pieter Vanderniepen for their technical assistance. The first author also would like to thank the fund from the China Scholarship Council (CSC) for the PhD funding. The authors acknowledge the financial support from Research Foundation - Flanders (FWO) for the scientific mission to the Paul Scherrer Institute (PSI). This research was performed in support of the European Project SILEX "Improving sustainability of construction materials using innovative siliconbased treatment", with project number LIFE11 ENV/BE/1046 and DO-IT Houtbouw.

\section{REFERENCES}

Van Acker J and De Smet J (2007) Moisture dynamics of plywood in exterior applications as a basis for service life prediction. In: Proceedings of the International Panel Products Symposium (IPPS 2007), Cardiff, South Wales, UK 47-60

Pleinert H and Lehmann E (1997) Determination of hydrogenous distributions by neutron transmission analysis. Physica B 234: 1030-1032

Van den Bulcke J, Van Acker J and De Smet J (2009) An experimental set-up for real-time continuous moisture measurements of plywood exposed to outdoor climate. Building and Environment 44 (12): 2368-2377

Li W. Z, Van den Bulcke J, De Windt I, Van Loo D, Dierick M, Brabant L and Van Acker J (2013) Combining electrical resistance and 3-D X-ray computed tomography for moisture distribution measurements in wood products exposed in dynamic moisture conditions. Building and Environment 67: 250-259

Chen S, Liu X, Fang L and Wellwood R (2009) Digital X-ray analysis of density distribution characteristics of wood-based panels. Wood Science and Technology 44 (1): 85-93

Masschaele B, Dierick M, Van Loo D, Boone M. N, Brabant L, Pauwels E, Cnudde V and Van Hoorebeke L (2013) Hector: A 240kv micro-ct setup optimized for research. In: 11th International Conference on X-Ray Microscopy 463

Manuel D, Denis V, Bert M, Jan V, Joris V, Veerle C and Luc V (2014) Recent micro-CT scanner developments at UGCT. Nuclear Instruments \& Methods in Physics Research Section B: Beam Interactions with Materials and Atoms 324: 35-40

Li W. Z, Van den Bulcke J, Mannes D, Lehmann E, De Windt I, Dierick M and Van Acker J (2014) Impact of internal structure on water-resistance of plywood studied using neutron radiography and X-ray tomography. Construction and Building Materials 73: 171-179

Li W. Z, Van den Bulcke J, De Windt I, Dhaene J and Van Acker J (accepted) Moisture behavior and structural changes of plywood during outdoor exposure. European Journal of Wood and Wood Products 